\title{
Barometric Pressure Effect on 5G Channel Model Validated using Convolutional Codes
}

\author{
Rahmattio Fa'is Baihaqi ${ }^{1}$, Khoirul Anwar ${ }^{2}$, and Rina Pudji Astuti ${ }^{3}$ \\ \{rahmattiobaihaqi@student., anwarkhoirul@, rinapudjiastuti@\} \\ Center for Advanced Wireless Technologies (AdWiTech) Telkom University ${ }^{1}$, School of Electrical \\ Engineering, Telkom University ${ }^{2}$
}

\begin{abstract}
The fifth telecommunication generation New Radio (5G-NR) is intended to utilize the millimeter wave (mmWave) band, which is sensitive to the natural conditions. 5G-NR requires channel modeling for optimal implementation, particularly for deployment in Indonesia, where the effect of the tropical condition is probably high especially due to the barometric pressure effect. This paper proposes 5G-NR channel model considering natural parameters of Bandung and Palembang, especially in Telkom University (Tel-U) and Universitas Sriwijaya (UnSri) areas, and observes the barometric pressure effects. We evaluate the $5 \mathrm{G}$ channel model, where outage performance is validated by frame-error-rate (FER) and bit-error-rate (BER) performances of 5G-NR cyclic prefix orthogonal frequency division multiplexing (CP-OFDM) numerology 2 with convolutional codes. The results show that lower barometric pressure affects on the increase of the number of path of $5 \mathrm{G}$ channel model. Outage performance and outage validation of $5 \mathrm{G}$ channel model in Tel-U and UnSri area has slightly different result due to barometric pressure effect.
\end{abstract}

Keywords: 5G-New Radio, Channel model, Channel capacity, Outage performance.

\section{Introduction}

According the needs of bandwidth, 5G-NR use the available channel in mmWave. The mmWave gives an attenuation caused by the environmental scale that increase the occurrence of blockage and penetration loss is highly dependent on the material [1]. The mmWave candidate for 5G-NR in Indonesia is divide into 3 frequency-band types which are $3.3 \mathrm{GHz}, 28$ $\mathrm{GHz}$ and $33 \mathrm{GHz}$ [2]. But, we predict that 5G-NR will use $28 \mathrm{GHz}$, in order to give available bandwidth up to $400 \mathrm{MHz}$ and in this working frequency, the attenuation can be tolerate compared to other mmWave that has been trialed measures in $6 \mathrm{GHz}-400 \mathrm{GHz}$ [3][4]. The mmWave have been tried to measure $5 \mathrm{G}$ channel model, in example 3GPP, METIS, Quadriga, mmMAGIC [4]-[5] Although these 5G channel modelling are not as good as NYUSIM to analyze channel conditions and spectral efficiency that it is use mathematical propagation approaches of the environment condition [6]. To validate the $5 \mathrm{G}$ channel models according to Indonesia's tropical climate, it will be evaluated by measurements of environmental conditions that cause results at New York University Simulation Model (NYUSIM) will be more accurate [7]. The 5G channel modeling research is adopted from a channel modeling exist in Europe and United Stated but they have different environment condition like barometric pressure. 


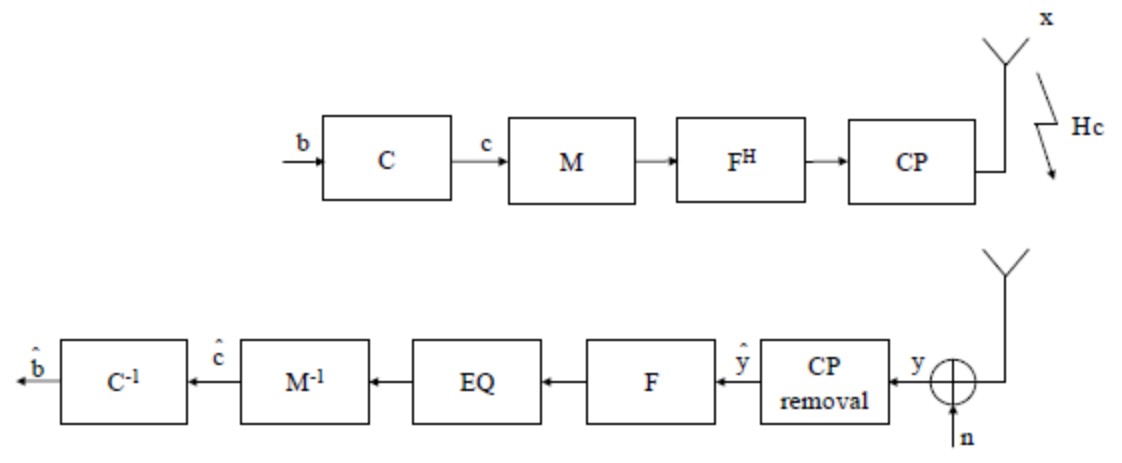

Figure 1. Systems model of to validate the proposed $5 \mathrm{G}$ channel model in Tel-U and UnSri area.

This paper proposes Tel-U 5G channel model by considering Indonesia's tropical condition especially barometric pressure that can be generate as representative Indonesia's environment by measure in two cities has different barometric pressure such as Bandung and Palembang city. The 5G-NR channel model is related to research in [8] and [9]. To acquire the 5GNR channel model, which is fundamentally represented in power delay profile (PDP), this paper considers (i) environment conditions estimation of channel modelling, as to adjust the genuine Indonesia's tropical climate and (ii) computer simulations, where NYUSIM is utilized to predict the channel model in Indonesia. The channel model is essential to determine the theoretical outage performance of 5G-NR in Indonesia by expecting Shannon' channel limit is accomplished by convolutional codes.

\section{Systems model of proposed 5G channel model}

The systems model of proposed $5 \mathrm{G}$ channel model is represented in Fig. 1, where $\mathbf{b}$ is information bits $\mathbf{b}=b_{1}, b_{2}, \ldots, b_{k}, \mathbf{C}$ is channel coding that using Convolutional codes encoder, $\mathbf{c}$ is coded bits $\mathbf{c}=c_{1}, c_{2}, \ldots, c_{n}, \mathbf{M}$ is Complex Binary Phase Shift Keying (C-BPSK) mapper based on [10], $\mathbf{F}^{\mathbf{H}}$ is IFFT block, $\mathbf{C P}$ is add Cyclic Prefix (CP) for 5G-NR CP-OFDM numerology 2 that we assume CP is longer than PDP length of 5G-NR channel model, $\mathbf{x}$ is transmitted bits, $\mathbf{H}_{c}$ are representative PDP of $5 \mathrm{G}$ channel model in Tel-U and UnSri area, $\mathbf{y}$ is received bits, $\mathbf{n}$ is AWGN, CP removal is remove $\mathrm{CP}$ of $5 \mathrm{G}-\mathrm{NR} \mathrm{CP}-\mathrm{OFDM}$ numerology 2, $\mathbf{F}$ is FFT block, EQ is equalizer, $\mathbf{M}^{-1}$ is C-BPSK demapper, $\mathbf{C}^{-1}$ is Convolutional codes decoder, $\hat{\mathbf{c}}$ is coded recieved bits $\hat{c}=\left\{c_{1}, c_{2}, \ldots, c_{n}\right\}$, and $\hat{\mathbf{b}}$ is recieved bits $\hat{b}=\left\{b_{1}, b_{2}, \ldots, b_{k}\right\}$.

\section{The proposed $5 \mathrm{~g}$ channel model framework}

In this paper, the proposed $5 \mathrm{G}$ Channel model focuses on the effect of barometric pressure on Tel-U and UnSri that it will use NYUSIM as tools for simulating the $5 \mathrm{G}$ channel model. This work will start by performing real-field measurements based on real environment which is Tel$\mathrm{U}$ with its barometric pressure and the measurement will be also carried out at UnSri as a comparison environment which has barometric pressure. 


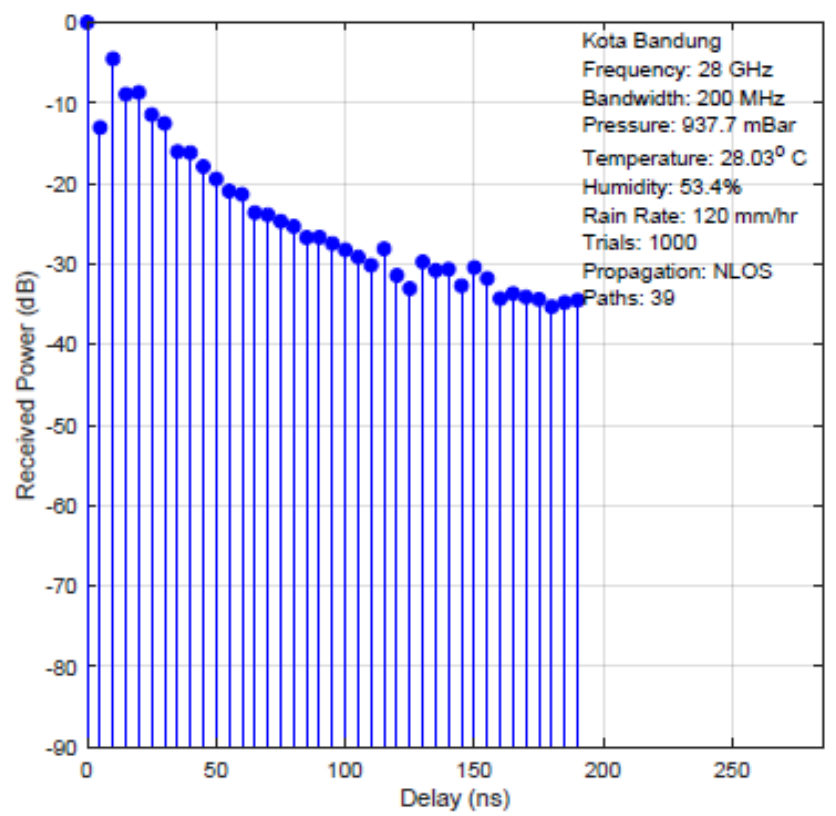

Figure 2. Representative PDP of proposed 5G channel model in Tel-U area.

Next the second step, the computer simulation using NYUSIM will be perform to obtain the PDP for each simulation.

In order to accuracy of the channel, representative PDP of the 5G channel model following steps are adjust the 3GPP standard [11]. Later, with the PDP obtained from previous simulation, we can calculated the value Cumulative Distribution Function (CDF). Every representative PDP construct a circulant matrix of the channel $\left(H_{c}\right)$, by using it we can calculate the outage probability vs SNR as outage performance.

In order to get the accurate measurement of the $5 \mathrm{G}$ channel model, outage performance should be validated by set up the agreement in gradients of outage performance, FER and BER of 5G-NR OFDM and convolutional codes. And also, the obtain 5G channel model validated by BER vs SNR performance of 5G-NR OFDM and convolutional codes.

\section{The proposed $5 g$ channel model}

The proposed $5 \mathrm{G}$ channel model is derived based on the representative PDP calculated from a thousand instantaneous PDP with 90 percentile CDF, where the minimum power of path is set to $-140 \mathrm{~dB}$ before normalized. The instantaneous PDP are obtained using NYU Wireless. Based on the measurement results, Tel-U has environment characteristic of average barometric pressure is 937 mbar, humidity of $53.4 \%$, temperature of $28.03\left({ }^{\circ} \mathrm{C}\right)$, rain rate $R_{0.01}$ is $120 \mathrm{~mm} / \mathrm{hr}$ [12]. Meanwhile, in UnSri has environment characteristic of average barometric pressure is 1006.89 mbar, humidity of $46 \%$, temperature of $30.6\left({ }^{\circ} C\right)$, rain rate $R_{0.01}$ is $132.1 \mathrm{~mm} / \mathrm{hr}$ [12]. 
Fig. 2 and Fig. 3 plots representative PDP of proposed 5G channel model in Tel-U and UnSri based on real condition parameter of environment has 39 and 38 paths, respectively.

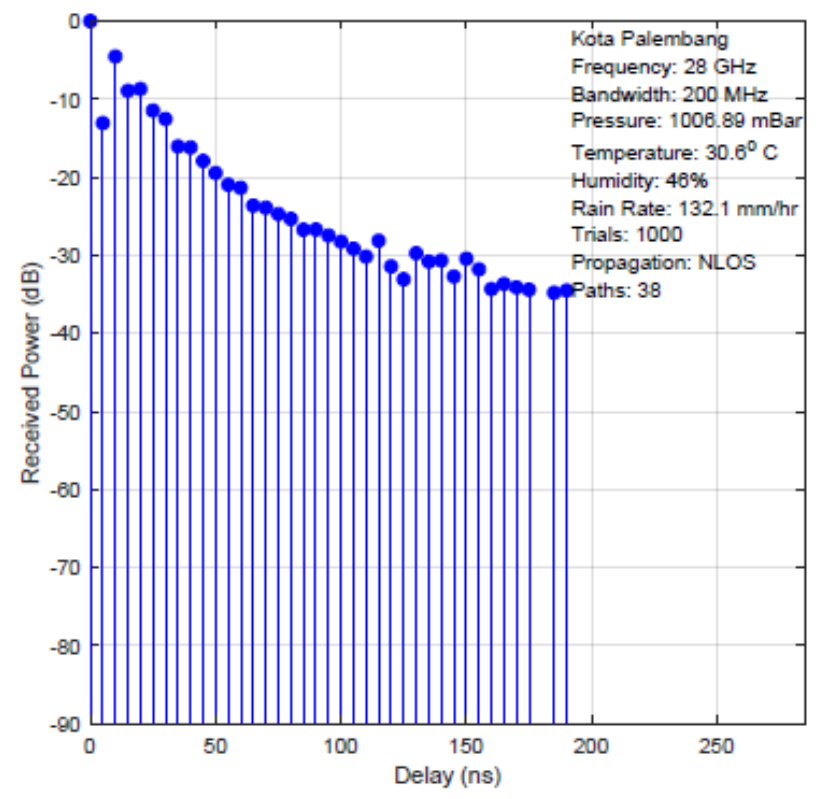

Figure 3. Representative PDP of proposed 5G channel model in UnSri.

\section{Performance evaluations of the proposed $5 \mathrm{~g}$ channel model}

The calculation of the capacity needed to avoid inter-symbol-interference (ISI). For multipath fading channels or broadband channel, the expected capacity is expressed as [13]

$$
C \approx \frac{B}{N} \sum_{n=1}^{N} \log _{2}\left(1+\left(\left|\psi_{n}\right|^{2} \cdot \gamma\right)\right)
$$

where $N$ is size of circulant matrix $\mathbf{H}_{c}$ that equal as a block transmission length of FFT size, $\gamma$ is the signal-to-noise power ratio (SNR) and $\psi$ is the eigenvalue of multipath channel. 5G-NR channel model obtained to bit rate that reached $20 \mathrm{GBps}$ which can be determined by equation (1) [13]in calculation of the capacity of the channel as

$$
C \approx \frac{B}{N} \sum_{n=1}^{N} \log _{2}\left(\operatorname{det}\left(1+\left(\left|\operatorname{diag}\left[F \cdot H_{C} \cdot F^{H}\right]\right|^{2} \cdot M \cdot R \cdot \frac{N_{F F T}}{N_{F F T}+Q} \frac{E_{b}}{N_{0}}\right)\right)\right) .
$$

where $B$ is $200 \mathrm{MHz}$ bandwidth of $5 \mathrm{G}-\mathrm{NR}$ in $28 \mathrm{GHz}, M$ is 1 bits per simbol of 5G-NR CBPSK, $R$ is $1 / 2$ coding rate of Convolutional codes, $Q$ is cyclic prefix length of 5G-NR CPOFDM numerology $2, E_{b} / N_{0}$ is Energy of the signal divided by noise density and $\mathbf{H}_{c}$ are representative PDP of 5G channel model in Tel-U and UnSri area, and $\mathbf{N}$ is an IFFT block that adjusts the size of the circulant matrix. 
The performance of $5 \mathrm{G}$ channel model can be determined by the capacity to evaluate the outage probability. Outage probability indicates the opportunities 5G-NR channel model transmission failure as expressed as [14]

$$
P_{\text {outage }}=P_{r}(R>C)
$$

This paper conducts a capacity calculation to observe the CDF of capacity for each representative PDP with barometric pressure effect. We present the outage performance and also outage validation of the proposed $5 \mathrm{G}$ channel model with Convolutional codes rates $R$ is 0.5 and

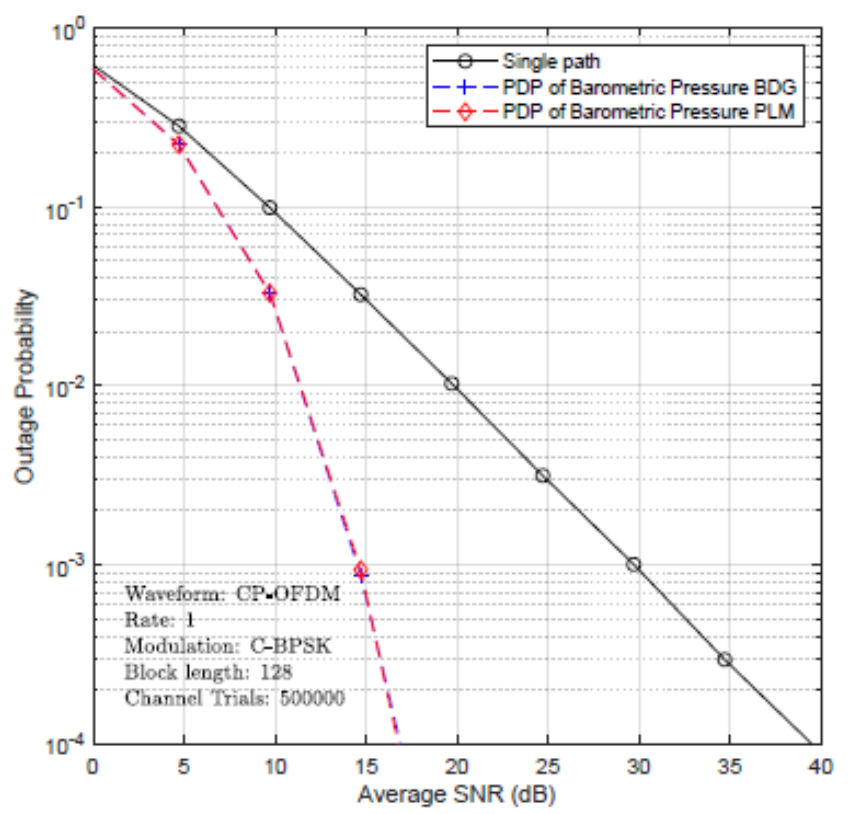

Figure 4. Outage performances of $5 \mathrm{G}$ system based on the proposed channel model.

SNR $0 \mathrm{~dB}$ until $40 \mathrm{~dB}$ as shown in Fig. 4 - Fig. 6. The Outage performances of $5 \mathrm{G}$ system based on the proposed channel model at Tel-U and UnSri are plotted by the outage probability toward $S N R$ as shown in Fig. 4. On the same SNR of $14.7 \mathrm{~dB}$, outage performance results are $8.74 \times 10^{-4}$ and also $9.38 \times 10^{-4}$, respectively. The outage probability curve of $5 \mathrm{G}$ channel model with lower barometric pressure in Bandung has better performances compared to higher barometric pressure in Palembang. And also, its better performance than single path that the utilization of CP-OFDM with channel coding helps the diversity effect of $5 \mathrm{G}$ transmissions to be achieved.

The FER performances for outage performance validation based on the proposed $5 \mathrm{G}$ channel model is shown in Fig. 5. There are FER performances gradient difference between Uncoded rate 1 curve and Convolutional codes rate 0.5 curve at $200 \mathrm{MHz}$ bandwidth. It caused the gap between the theoretical outage and uncoded CP-OFDM curve that can be reduced by 
utilizing a strong capacity achieve channel coding. On SNR $34.7 \mathrm{~dB}$, the outage validation on $5 \mathrm{G}$ channel model in Tel-U and UnSri area by convolutional codes is $4.35 \times 10^{-4}$ and $4.5 \times 10^{-4}$, respectively. On the same SNR, these outage performance and outage validation of $5 \mathrm{G}$ channel model in Tel-U and UnSri area has different curve results occurs due to barometric pressure effected.

Fig. 6 shows the BER performance, where the gap between convolutionally coded system and uncoded system under $5 \mathrm{G}$ channel model begins with $3.5 \mathrm{~dB}$ at BER of $10^{-2}$.

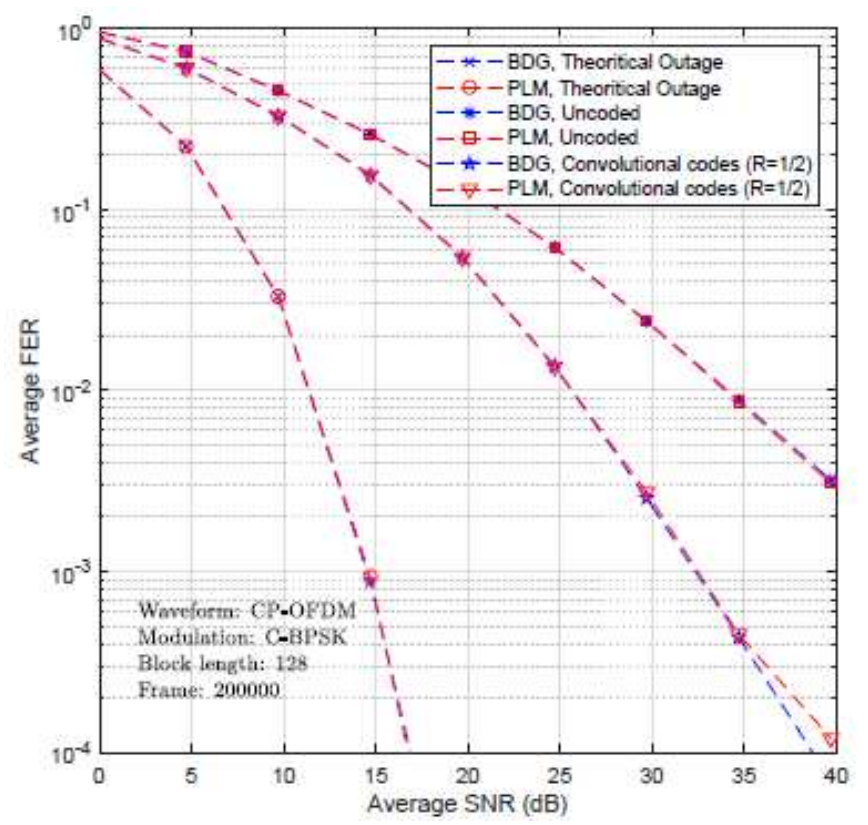

Figure 5. FER performances for outage performance validation based on the proposed $5 \mathrm{G}$ channel model.

These validations are provide BER that outage performance has agreement gradient. Furthermore, the outage performance and SNR values are expected to become a reference for $5 \mathrm{G}$ system implementation in Tel-U, UnSri and Indonesia. 


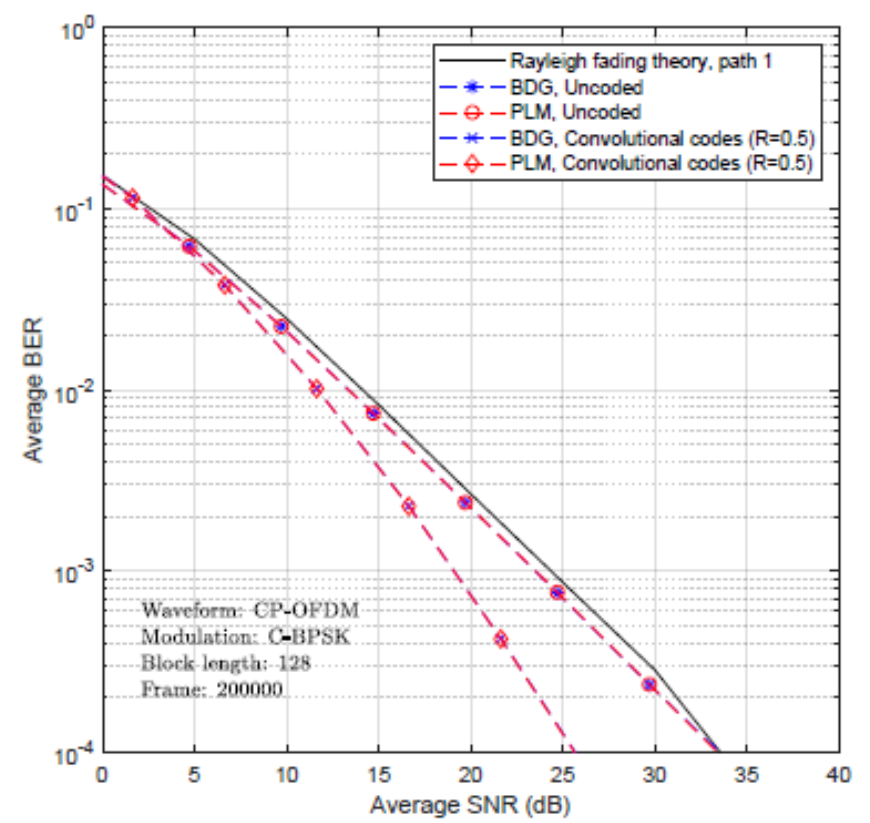

Figure 6. BER performances for outage performance validation based on the proposed $5 \mathrm{G}$ channel model.

\section{Conclusion}

This paper has proposed 5G Channel Model under barometric pressure effect derived for Tel-U and UnSri area, which is validated using BER and FER performances using Convolutional Codes, and 5G-NR CP-OFDM numerology 2 and 5G-NR C-BPSK. This paper has provided 5G Channel Model being specific in Indonesia's tropical climate. The results shows that lower barometric pressure affects on the increase of the number of the PDP path, outage performance and outage validation of $5 \mathrm{G}$ channel model in Tel-U and UnSri area.

\section{References}

[1] T. S. Rappaport, Y. Xing, G. R. Maccartney, A. F. Molisch, E. Mellios, and J. Zhang, "Overview of Millimeter Wave Communications for Fifth-Generation (5G) Wireless Networks-with a focus on Propagation Models," 2017.

[2] "PERATURAN MENTERI KOMUNIKASI DAN INFORMATIKA REPUBLIK INDONESIA TENTANG - PDF Download Gratis.” [Online]. Available: https://docplayer.info/32099657Peraturan-menteri-komunikasi-dan-informatika-republik-indonesia-tentang.html. [Accessed: 16Jan-2020].

[3] T. S. Rappaport et al., "Millimeter Wave Mobile Communications for 5G Cellular: It Will 
Work!," doi: 10.1109/ACCESS.2013.2260813.

[4] S. Sun, T. S. Rappaport, M. Shafi, P. Tang, J. Zhang, and P. J. Smith, "Propagation Models and Performance Evaluation for 5G Millimeter-Wave Bands," IEEE Trans. Veh. Technol., vol. 67, no. 9, pp. 8422-8439, Sep. 2018, doi: 10.1109/TVT.2018.2848208.

[5] L. Raschkowski, P. Kyösti, K. Kusume, and T. Jämsä, "Deliverable D1.4 METIS Channel Models."

[6] S. Sun, G. R. Maccartney, and T. S. Rappaport, ""A novel millimeter-wave channel simulator and applications for A Novel Millimeter-Wave Channel Simulator and Applications for 5G Wireless Communications," 2017.

[7] I. Abubakar, J. Din, and H. Y. Lam, "Disparities in the Induced Rain Attenuation between Beacon (Narrowband) and Broadband Satellite Links in Tropical Zones," Indones. J. Electr. Eng. Comput. Sci., vol. 10, no. 2, pp. 687-695, 2018, doi: 10.11591/ijeecs.v10.i2.pp687-695.

[8] E. M. Alfaroby, N. M. Adriansyah, and K. Anwar, "Study on channel model for Indonesia 5G networks," in 2018 International Conference on Signals and Systems, ICSigSys 2018 Proceedings, 2018, pp. 125-130, doi: 10.1109/ICSIGSYS.2018.8372650.

[9] K. Anwar, E. Christy, and R. P. Astuti, “Indonesia 5G Channel Model Under Foliage Effect Model Kanal 5G Indonesia dengan Pengaruh Dedaunan Center for Advanced Wireless Technologies (AdWiTech), School of Electrical Engineering," Bul. Pos dan Telekomun., vol. 17, no. 2, pp. 75-94, 2019, doi: 10.17933/bpostel.2019.170201.

[10] TSGR, "TS 138201 - V15.0.0 - 5G; NR; Physical layer; General description (3GPP TS 38.201 version 15.0.0 Release 15)," 2018.

[11] "3GPP specification status report." [Online]. Available: https://www.3gpp.org/DynaReport/status-report.htm. [Accessed: 16-Jan-2020].

[12] S. Zaiummi, M. Zawawi, N. Fairuz Fauziz, R. Maria, M. Yeh, and J. S. Mandeep, Study of Prediction Models Compared with the measurement Results of Rainfall Rate and Ku-Band Attenuation at Indonesia. .

[13] J. B. Anderson, A. Board, J. Hagenauer, R. Johannesson, and N. Beaulieu, IEEE Press Series on Digital \& Mobile Communication Books in the IEEE Press Series on Digital \& Mobile Communication. .

[14] "UVMHN Career - $\quad$ Workday." [Online]. Available: https://uvmhealth.wd1.myworkdayjobs.com/EXTERNAL_UVMHN/job/BurlingtonVT/Network-Director-of-DigitalStrategy_R0011262?utm_source=localiq\&utm_medium=search\&utm_campaign $=$ shortterm 1 . [Accessed: 16-Jan-2020]. 